\title{
Late Effects and Long-Term Follow-Up
}

\author{
Michelle Kenyon, John Murray, Barry Quinn, \\ Diana Greenfield, and Eugenia Trigoso
}

\begin{abstract}
Allogeneic stem cell transplantation was successfully performed in 1968, and its use has grown significantly over the past five decades with the total number now exceeding 1 million patients. HSCT is a curative treatment for many haematological cancers and other disorders. Almost 40,000 HSCT procedures are performed Europe-wide per annum (Passweg et al., Bone Marrow Transplant, 2016), and with a 5-year survival around 50\% (Friedrichs, Lancet Oncol 11(4):331-338, 2010), the number of transplant recipients achieving 'long-term survival' and with late effects directly related to their treatment (Majhail et al., Hematol oncol Stem Cell Ther $5(1): 1-30,2012)$ is increasing. This growth in survivors is the result of improvements in transplant knowledge and expertise, refinements to conditioning regimes, developments in supportive care and increased numbers of procedures due to broadening transplant indications.

The most common cause of death after transplant is relapsed disease. Yet, even without disease relapse, long-term survival is complex for many as other causes of mortality such as graft versus host disease (GvHD), infection, second malignancy, respiratory disease and cardiovascular disease (CVD) (Savani et al., 2011) prove difficult to address.
\end{abstract}

M. Kenyon $(\bowtie)$

Department of Haematological Medicine,

King's College Hospital NHS Foundation Trust, London, UK

e-mail: michelle.kenyon@nhs.net

J. Murray

Haematology and Transplant Unit, The Christie NHS

Foundation Trust, Manchester, UK

B. Quinn

Palliative Care Department, Woking and Sam Beare

Hospices, The Goldsworth Park Centre, Woking,

Surrey, UK

\section{Greenfield}

Department of Oncology and Metabolism,

Sheffield Teaching Hospital NHS Foundation Trust, University of Sheffield, Sheffield, UK

E. Trigoso

Paeidatric Transplant Unit, Hospital Universitario y Politécnico LA FE, Valencia, Spain 
Recovery post-HSCT is challenging, lasting several months to years. These individuals are susceptible to the development of post-treatment physical and psychological sequelae years to decades after completion of treatment leading to a reduced life expectancy with greater morbidity when compared to an age-adjusted population (Socié et al., N Engl J Med 341:14-21, 1999). Survivors with late effects experience significantly poorer physical and mental health, report more unmet needs for care and have significantly greater use of health services compared with survivors without late effects (Treanor et al., Psychooncology 22(11):2428-2435, 2013).

Furthermore, as the number of survivors continues to grow, their longterm health problems and subsequent needs demand increasing attention.

The unpredictable, complex and multifactorial nature of these longterm and late effects in HSCT survivors means that patients require regular life-long assessment guided by rigorous protocols. However, it is important to remember that even using standardised protocols, these should be different for adults and children and the resulting care must be tailored to the needs of the individual survivor. And finally, further consideration is needed for the growing number of young people and adult survivors in long-term follow-up who have been treated in childhood and transitioned into adult long-term follow-up care.

\section{Keywords}

Late effects • Survivorship $\bullet$ Survivors $\bullet$ Follow-up

\subsection{Principles of Care}

Protocol-led assessment and treatment is included in the current FACT-JACIE standards (version 6), which has evolved the standard of care recommending the assessment of recipients for evidence of acute and chronic GVHD, need for vaccinations and post-transplant late effects.

\begin{abstract}
There should be policies and procedures in place for monitoring by appropriate specialists of recipients for post-transplant late effects, including at a minimum endocrine and reproductive function, osteoporosis, cardiovascular risk factors, respiratory function, chronic renal impairment, secondary cancers, and the growth and development of pediatric patients. (Standard B7.6.8)
\end{abstract}

A further benefit of life-long survivorship care is the acquisition of knowledge and understanding through data collection and analysis which in turn facilitates the design and delivery of appro- priate services that will better meet the needs of future survivors.

*Late effect: A health problem that occurs months or years after a disease is diagnosed or after treatment has been administered. Late effects may be caused by the primary disease or its treatment and may include physical, mental or social problems and/or secondary cancers.

\subsection{Survivorship and Quality of Life}

While there are many definitions of survivorship, it is widely accepted that a survivor is anyone living after a diagnosis of cancer or 'living with and beyond cancer'.

Survivorship includes 'those who are undergoing primary treatment, those who are in remission following treatment, those who are cured and those with active or advanced disease' (DoH 2010). 
By developing and implementing strategies to improve the care and support for HSCT survivors, we will also improve their quality of life and experience of care.

There are a broad range of issues experienced by HSCT survivors which are detrimental to overall quality of life (QoL) and have been reported in the literature.

Unmet physical or psychological needs are reported in $60 \%$ of cancer survivors. Beyond the first post-HSCT year, a fifth report psychosocial difficulties including fatigue, social reintegration, finance and employment. A third worry about the future and their health (Baker et al. 1999; Andrykowski et al. 2005; Gielissen et al. 2006).

Finance, employment and education are leading survivor concerns. The economic cost of cancer is a substantial personal and societal problem; $92 \%$ of sufferers lose income, impacting adversely on QoL for $40 \%$ (Bieri et al. 2008). These are among the major challenges that significantly hinder the cancer patient survivorship transition from treatment phase to reintegration phase and limit the postHSCT potential for personal growth and fulfillment.

Work and education are immensely important to cancer survivors (Snyder 2002) and have health benefits, and interventions addressing return to work are cost-effective (Waddell and Burton 2006). Reintegrated survivors are more likely to self-manage (Richards 2013), make a positive contribution to self and society, depend less on the state financially and potentially reduce healthcare costs.

A range of psychological and psychosocial interventions including education, exercise, counselling, cognitive behavioural therapy (CBT) and psychotherapy have been investigated, aiming to address survivor concerns and improve overall quality of life.

\subsubsection{Quality of Life Assessment}

There is a new emphasis on understanding and monitoring the concerns and outcomes for cancer survivors through the routine use of patientreported outcome measures (PROMs) in followup services. Quality of life (QoL) is an important outcome measure following HSCT. Treatmentspecific QoL tools exist and have been validated in patients receiving haematopoietic stem cell transplant.

Instruments for assessing QoL can be general or specific to a certain disease or treatment. A number of cancer-specific tools (QLQ - LEU, EORTC SF 36, FACT-G/ FACT-BMT) exist and can be seen in publications of large-scale studies. They are often holistic, assessing different dimensions of well-being, such as physical, emotional, social/family and functional. Many of the commonly used scales such as EORTC and FACT are self-complete and produce a numeric score from which an inference on the relative QoL can be drawn.

These holistic assessments can be used to collect information on individuals at set time points during treatment and recovery and also can increase our knowledge of our patients as a group or groups. QoL data can help us to understand the differences between groups, e.g. comparing QoL in male versus female recipients or haploidentical versus cord recipients.

Standardised assessment tools can reveal information in certain groups or individuals that may not have been previously identified through conventional outpatient consultation alone. This can lead to increases in referrals to other services such as counselling, assisted conception, sexual dysfunction, social work, etc.

At a local level, this increase in referrals can have resource implications, but it can also lead to:

- Formalising referral pathways

- Cultivating interest and expertise in certain areas

- Developing services that meet the unmet holistic needs of the patients

Furthermore, this information can be used to:

- Identify how quality of life can be improved for individuals and to help plan holistic care for individual patients 
- Assess quality of care in individual services

- Measure progress on survivorship care across networks or countries

This holistic approach to assessment identifies individual information needs. These needs can be met through a discussion with a healthcare professional, which is supported by written or multimedia materials and offers signposting for individuals to high-quality information and support (Table 14.1). The table below illustrates the most common issues expressed through assessment. They are multidimensional in nature representing psychological, physical and functional concerns.

\subsubsection{Common Post-HSCT Concerns}

\subsubsection{Physical Well-Being}

Most studies found that survivors report resumption of routine physical activities but describe a greater number of medical problems (Mosher et al. 2009). Fatigue is one of the most commonly reported concerns, and many HSCT patients are dissatisfied with their energy levels many years after treatment. Providing information materials and education on fatigue management is a key area where nurses can positively influence this troubling issue (Anderson et al. 2007; Andorsky et al. 2006).

Table 14.1 Top 10 common concerns (www.eHNA/ Macmillan.org.uk analysis 2015)

\begin{tabular}{|c|l|}
\hline 1. & Worry, fear or anxiety \\
\hline 2. & Tiredness, exhaustion or fatigue \\
\hline 3. & Sleep problems/ nightmares \\
\hline 4. & Pain \\
\hline 5. & Eating or appetite \\
\hline 6. & Anger or frustration \\
\hline 7. & Getting around (walking) \\
\hline 8. & Memory or concentration \\
\hline 9. & Hot flushes/ sweating \\
\hline 10. & Sore or dry mouth \\
\hline
\end{tabular}

Accessed Aug 2016

\subsubsection{Psychological Distress}

It is known that $5-19 \%$ of HSCT survivors exhibit symptoms that are consistent with posttraumatic stress disorder (PTSD). In those without PTSD, four out of ten report clinically significant psychological distress at an average of 3.4 years post-transplant. The same study found that there was no difference by age, gender, transplant type or time following transplant (Rusiewicz et al. 2008).

\subsubsection{Return to Work}

HSCT survivors return to work despite ongoing physical and psychological symptoms. Younger age and higher levels of education have been linked to a higher probability of post-transplant employment. Those who are unsuccessful in returning to work have poorer physical, cognitive and social functioning and report more pain, sleep disorders and distress (Mosher et al. 2009).

While return to work or education is important to survivors, in guiding our patients, it is essential to consider the following:

- Type of work

- Physical demand

- Environment

- Routine

- Hours

- Support of employer

- Phased return is usually the optimal way of enabling people to return to work progressively

- Financial pressure

- Many people need to return to work due to mounting financial difficulties

- Self-esteem

- Some people feel 'lost' without their work identity and feel a sense of urgency to return

\subsubsection{Sexuality}

Evidence suggests that sexual function is one of the most prevalent and persistent long-term concerns after HSCT. 
Fig. 14.1 Range of concerns in relation to sexual response cycle (Adapted from Greenfield 2012 www.ebmt.org accessed Sept 2016)

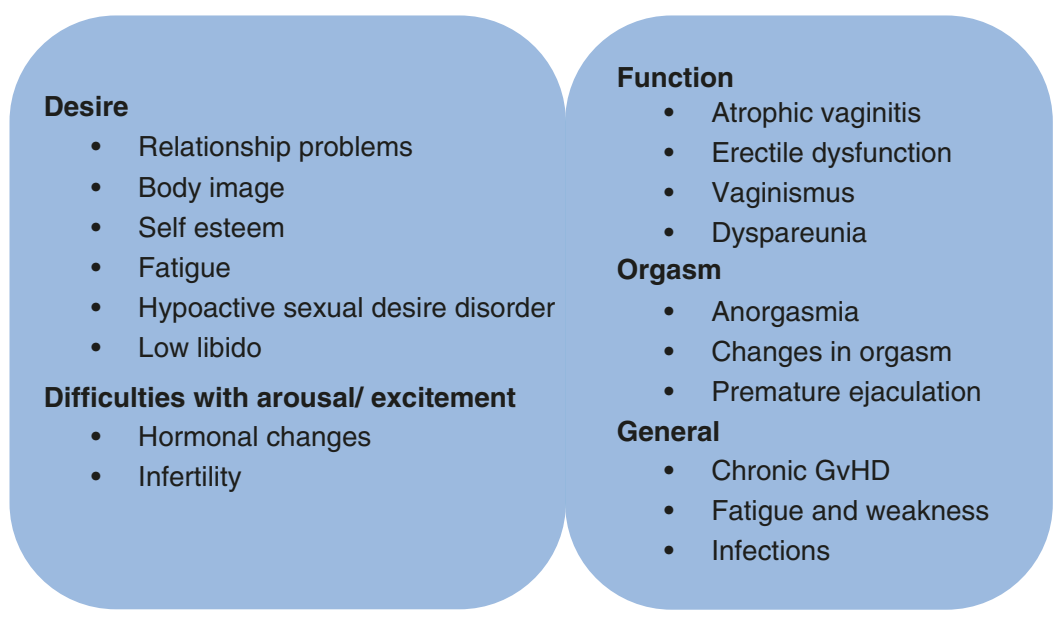

Despite its prevalence and the range of concerns that can be experienced across the entire sexual response cycle (Fig. 14.1), sexual function issues are under-reported. However, a range of sexual concerns have been described with a tendency for women to report more problems than men and women continue to describe more sexual concerns a number of years post-transplant (Mosher et al. 2009). Sexual function is typically multifactorial in origin with endocrine, mechanical and psychological factors. People may benefit from relaxation, massage therapy, aromatherapy or other complementary procedures. Those that resume sexual relations in the first post-transplant year tend to experience fewer long-term issues (Jean and Syrjala 2009).

\subsection{Addressing Sexuality}

Sexuality is a part of each person's life and identity and is much more than the physical act of sexual intercourse or sexual expression. It is also about less obvious components including how people perceive themselves as sexual beings and the need to be recognised, connected with, loved and cared for by others. Whether the person is in a relationship (gay, lesbian, heterosexual), is single or enjoys sex with one or multiple part- ners, most people will have sexual needs and desires throughout their life (Osho 2002; Williams 2003; Quinn 2010). There is a danger that in seeing sexuality as merely a physical expression that the haematology and transplant care team may fail to see that sexuality is about the whole person including how they relate to others in an intimate way. Whether the patient is or is not sexually active during the prolonged treatment period before, during and after transplant, patients will need support and advice from the team caring for them, on sexual changes, choices and concerns.

Sex and sexuality are largely seen as a very private matter, and a patient and/or partner may be reluctant to talk about their concerns or unexpected changes to a member of the transplant team who appear busy dealing with other aspects of the treatment process (Schover 1997; Twigg 2000; Mulhall 2008). It is important that the team make it clear that they are there to help with sexual changes and worries and to know what help is available.

There may be a misconception from some members of the transplant team that a person undergoing a stem cell transplant will not have an interest in sex. In reality, whether a person is in a relationship or not, human beings are born as sexual human beings and will die as sexual human beings (Quinn 2010). What that means for each person and how they will express that need throughout periods of their life 
will change. For some, people being sexually intimate with their partner during the treatment and transplant process may bring comfort, reassurance and hope amidst ongoing uncertainty and change, while others will have no interest in being sexually active. However, feeling loved, accepted and cared for as one faces the uncertainty of transplantation may bring great comfort to the person and their partner (Schover 1997).

In a busy haematology or transplant setting, the team can help to facilitate times of privacy when the individual can be alone or with their partner if this is what they wish. The transplant team who recognise the importance of these intimate moments can often organise treatments and interventions, at less acute points in the transplant process, in order to provide these moments or times of privacy.

The diagnosis of cancer or indeed any illness and the treatments and changes required may have a profound impact on the person and partner, affecting them physically, emotionally, socially and spiritually (Murphy 1990; Brandeburg et al. 2010). For example, facing the reality of temporary or permanent infertility and the multiple body and life changes secondary to disease and treatments can affect a person's sexual identity. The physical and psychological demands of dealing with a serious illness, the transplant demands and setting can interfere with the human sexual response cycle (desire/interest, arousal, readiness (penetration), orgasm and resolution, satisfaction). Any of these points on the response cycle may be affected but can be sensitively addressed (Schover 1997). The team can sensitively support the person and the partner through the transplantation process and treatments mindful of the impact on the person's sexual being. This includes providing accurate information on potential sexual changes that may occur, practical advice on the choice of treatment and interventions and a listening ear. Many sexual concerns arising in the haematology and transplant setting can be resolved or certainly reduced by a member of the team simply listening to the person's concerns and knowing how and where to access practical and expert help, if required (Schover 1997; Quinn 2010).

While some of the changes to the person's sexuality may appear obvious, many of the more profound changes that a person may face and the impact they have on an individual are often hidden and not so obvious to others (Murphy 1990). Many of the treatments and changes required in the transplant process can affect a person's sexuality including how they relate to their own body and to others (Schover 1997).

It is worth considering the impact of other comorbidities the person may have and the treatments required for these conditions and how these too may affect their sexuality and their ability to have sex. In addressing sexual concerns, the transplant team can be proactive in supporting the person with body changes and psychological concerns that may be interfering with their sexual identity and sexual expression.

Members of the transplant team who are aware of the possible impact that treatments, the transplant protocol and supportive medications may have on a person's sexuality will be better able to speak to the person sensitively, honestly and clearly before the commencement of treatment. These issues should be an important part of the preparation for treatment and transplantation (Quinn 2010). Support may take the form of practical advice, including adjusting to an altered sex life during treatment, adequate pain/symptom control, comfortable positioning during sex, contraception, providing private moments, advice on sexual aids and medical treatments or simply an opportunity to talk about concerns and fears (Table 14.2). Practical support and guidance can help the person returning to sexual activity after transplantation or simply regaining confidence in being sexually expressive again.

Many of the treatment agents (chemotherapy, targeted therapies and radiation) used in the field of haematology and transplantation are known to cause specific problems which can lead to lower sex drive, vaginal dryness (which may cause pain during intercourse), erection concerns, ejaculation and orgasm difficulties (which may lead to loss of con- 
Table 14.2 Providing support (Quinn 2010)

Sensitively listening and addressing fears

Creating time and privacy for couples to be alone

Providing adequate symptom relief

Support with body changes

Encouraging couples/sexual partners to talk to one another

Advice on creative foreplay (hugging, stroking, having a shared bath, kissing, mutual masturbation)

Advice on alternative positioning

Alternatives to sexual penetration

Guidance on sexual aids (dilators, vacuum pumps, dildo, toys)

Guidance on medical treatments (oral, injection, pellets)

Counselling

fidence and lack of sexual enjoyment) (Brandenburg et al. 2010). Some drugs including the vinca alkaloids and some targeted therapies may cause nerve damage giving rise to erectile dysfunction and to ejaculation and orgasm difficulties. Following total body irradiation, a small number of patients may experience damage to the nerve, vascular and muscle tissue giving rise to possible erectile difficulties, including the inability to get or maintain an erection suitable for sexual penetration or vaginal changes including stenosis and/or dryness which may cause pain during sexual intercourse.

Women may benefit from the team explaining the use of vaginal lubricants and dilation to prevent vaginal stenosis. Men may require support in exploring treatment options for erectile concerns. These complications may require interventions including advice on oral medications (sildenafil, tadalafil, vardenafil), pellet (intraurethral alprostadil) (MUSE), injection (intracavernosal alprostadil) and appliances (vacuum device) to address erectile dysfunction. Hormone replacement therapy unless contraindicated may have a place, an opportunity to talk through fears and concerns and/or psychosexual therapy support (Brandenburg et al. 2010).

If patients are sexually active during treatment, the team should advise them to use some form of barrier method (condoms, femidoms, dental dams) (Quinn 2010). This is to protect the patient's partner from the minimal risk of irritation caused by a small amount of chemotherapy agents remaining in bodily fluids such as semen, urine and rectal and vaginal secretions. These barrier methods may also reduce the risk of infection especially if the patient is at risk of neutropenia and prolonged immunosuppression. While individuals are advised to take steps to prevent infection, rarely should this prevent the person from enjoying sex with a partner. Occasionally the team may learn of partners no longer sleeping in the same bed for fear of contamination to their partner; the team can reassure the couple that this is not necessary and they can continue with their usual sleeping arrangements. The team can also be sensitive to the demands made and the concerns that arise on the person or couple due to the transplant process.

Other sexual difficulties may arise due to body changes and other symptoms including weight gain or loss, skin changes, graft versus host disease, constipation, diarrhoea, nausea, fatigue, oral complications, depression and anxiety. The person's confidence in being sexual active may be affected by the unwanted body changes that occur. Poorly controlled symptoms, such as nausea, vomiting, constipation, diarrhoea, loss of appetite and extreme tiredness caused by the treatments and the underlying disease, may affect the person physically and psychologically. Carefully assessing and managing these symptoms may enable the person to enjoy the comfort of sexual intimacy with their partner (Schover 1997).

Some of the supportive treatments used in the transplant setting while bringing relief to these unpleasant symptoms can also give rise to sexual difficulties. Pain relief including opiates may give rise to uncomfortable constipation, tiredness, nausea and mucosal dryness leading to painful vagina/ anal intercourse and erectile dysfunction. Some anti-sickness medication while providing necessary relief from nausea can effect erectile functioning. While antianxiety and anti-depressant mediations help with stress and anxiety, these medications can lead to a lower sex drive, erectile 
dysfunction, ejaculatory and orgasm difficulties and vaginal dryness (Quinn 2010).

Many of the chemotherapy agents used in the haematology and transplant setting can affect the person's fertility including alkylating agents which are known to cause most damage, resulting in either temporary or permanent infertility. For many young patients, this may be the first time that they have had to consider the possibility of planning children, and this will require support from the team, family and friends. Facing the possibility of being infertile can have a profound effect on how the person feels about themselves and their place in the world.

Patients will be advised not to plan children during the treatment as the drugs and the demanding treatment requirements will affect the development of the embryo leading to foetal defects and miscarriage. For some people/couples, it may be very painful having to put their plans for a family on hold during the treatment and transplant period. Occasionally a woman may discover a cancer diagnosis during her pregnancy and may be advised to undergo a medical termination because the pregnancy will not be viable and/or in order to proceed with necessary treatment. This can be a very difficult time for the woman and her partner; sometimes the full impact of this loss becomes more apparent following the completion of treatment.

The team can be there to talk about the impact of treatment and to support and advice on the possible options available to support fertility (Schover 1997). For men this may include sperm banking and the possibility of cryopreservation of testicular tissue, generally used for younger patients. For women, this may include cryopreservation of embryos or eggs and ovarian preservation. In some cases, the urgency of treatment may mean that fertility-saving options are not possible. During the transplant process, the focus for everyone including the patient may be on treating the disease, and the reality of being infertile becomes more important in the months and years following transplantation. This can be extremely difficult for patients who are beginning new relationships and have to disclose this to their new partner. This reality can be addressed at follow-up clinics both in the hospital and community, ensuring the person has support that they can access. Individuals and couples may need support and advice over their concerns of having passed or passing on genes to their children predisposing them to a higher risk of cancer (Quinn 2010).

Some patients will be at risk of bleeding due to thrombocytopenia and should be advised to continue a sex life if they so wish but to be aware of reducing trauma during sex, including vaginal, oral and anal intercourse. Localised trauma may be reduced by using a more gentle thrusting movement during penetration or masturbation.

Many of the drugs used in the transplant setting may bring on the early onset of menopause and the associated symptoms which can cause great distress. Medically induced menopause brings unwanted symptoms including vaginal dryness, mood changes, hot flushes, low confidence and sometimes a lack of interest in sex. Women may find it more difficult to achieve a satisfactory orgasm (Brandenburg et al. 2010). It is important that women and their partners are forewarned about these symptoms but also to ensure these issues are revisited sensitively during and after treatment.

Men and women may need support and advice on finding alternative ways to express themselves sexually both during and after transplant. Although men and women may have a reduced interest in sex for a period of time, their interest in returning to a sexually active relationship may return in weeks and months following the transplant.

Practical measures including the careful positioning of medical devices may enable a person to be held and hugged during prolonged hospitalisation. These measures also include reducing clutter around the persons' bed so that their partner can be closer to them and critically reviewing and removing any unnecessary infection control measures that may act as a barrier to intimacy. Practical advice on how to deal with medical devices including urinary catheters and emptying bowels and/or bladder before having sex can provide greater comfort. While the person may lack the energy 
to participate in sexual intercourse, they may wish to try alternatives including cuddling, hugging, lying in bed together, increased time for foreplay, sharing a bath or shower together and sharing quiet and private moments together (Schover 1997).

Although the sexual needs of patients in the highly technically setting of transplantation can sometimes be overlooked, the ability to be intimate with a partner might be a welcome relief from some of the demands made on the person by the transplant process.

\subsection{Summary}

\subsubsection{Wider Impact of Survivorship Care}

Carers of those with cancer report high levels of emotional distress. The psychological difficulties that carers report can be prolonged. This is exacerbated by their own lifestyle and role disruption; carers report financial difficulties and are often unable to work for periods themselves or have to give up work altogether due to their 'carer role' commitment. It is important to recognise these issues and offer carers support and information.

\subsubsection{Models of Long-Term Follow-Up}

It is widely recognised that HSCT recipients require structured long-term follow-up and screening to reduce the morbidity and mortality demonstrated in those considered as long-term survivors.

There are clear guidelines around screening requirements (Majhail et al. 2012) but little direction on how these might best be implemented in a late effects (LE) service. A survey of UK transplant centres identified that all had a LE service and most had a standard operating procedure outlining its process but identified wide variability in almost every aspect of the late effects services (Hamblin et al. 2017).
Important components for successful delivery of LE service include:

- Assessment tools incorporating clinical and psychosocial late effects

- Availability of a range of medical and allied health specialists

- Access to psychological services

- Implementation of second malignancy screening, e.g. mammography and PAP smear

\subsubsection{Opportunities for Nurses}

Nurses have a significant role in delivering and/or coordinating post-HSCT care for patients.

Nurses have an opportunity to:

- Identify useful resources for patients

- Develop post-HSCT services for patients

- Ensure that care meets the needs and concerns of patients

- Develop innovative roles as individual practitioner and as part of a wider multidisciplinary team

- Develop the evidence base by leading/participating in survivorship research

- Develop creative ways of working and providing suitable clinical and supportive care

\subsection{Post-transplant Complications and Surveillance}

Standardisation of follow-up protocols is important to prevent important tests being overlooked or being duplicated unnecessarily.

\subsubsection{Second Malignancies}

There is an increased risk of developing a second solid cancer post-transplant in the range of 2-6\% at 10 years. Data suggests that second solid cancers occur twice as frequently in the transplant population than in the general public with this 
increasing to threefold at 15 years. There are several risk factors that may contribute to the development of a second solid cancer (Curtis et al. 1997):

- Total body irradiation

- Primary disease

- Male sex

- Pre-transplant conditioning

- Genetic predisposition contributing to initial cancer and subsequent malignancy

Clinicians have long been aware that radiation leads to second solid cancers with a latent period of approximately 3-5 years before developing a malignancy (Rizzo et al. 2009). The risk for nonsquamous cell cancer is higher in younger patients (especially those under 30 years) at ten times that of nonirradiated patients. Other cancers such as breast, thyroid, brain, central nervous system, bone and connective tissue and melanoma are all related to radiation exposure. Screening for some of these cancers is available and aids in early diagnosis (Savani et al., 2011).

All patients should be enrolled into national cancer screening programmes for breast, cervical, colon and skin cancer. Particular attention should be paid to women who receive radiation to their chest $>800$ cGy to ensure they follow guidelines laid down for paediatric survivors. These state that annual mammogram screening should begin at 25 years of age or 8 years after exposure whichever occurs later. Women should have PAP smears annually to three yearly, and those with GvHD should be screened annually. Patients should have at least six monthly dental reviews and an annual thyroid assessment, and if any thyroid nodule is identified, imaging and potential biopsy should be undertaken (Savani et al. 2011).

At the initial consent for transplant consultation, patients should be counselled about the future potential risks of second malignancy. This is an ideal time to engage with the patient and help them make changes to their lifestyle that will have an impact on their lives moving forward. Smoking cessation, a healthy balanced diet, taking regular exercise, reducing alcohol consumption and taking care of their skin in the sun will all have beneficial effects.

\subsubsection{Systematic Post-transplant Screening and Investigations}

A specific screening plan for transplant patients has been published by Majhail et al. (2012) on behalf of the Center for International Blood and Marrow Transplant Research (DeFilipp et al. 2016), American Society for Blood and Marrow Transplantation (ASBMT), European Group for Blood and Marrow Transplantation (EBMT), AsiaPacific Blood and Marrow Transplantation Group (APBMT), Bone Marrow Transplant Society of Australia and New Zealand (BMTSANZ), East Mediterranean Blood and Marrow Transplantation Group (EMBMT) and Sociedade Brasileira de Transplante de Medula Ossea (SBTMO).

These comprehensive guidelines written by an expert group in 2006 and updated in 2011 provide a consensus for screening and preventative measures for autologous and allogeneic stem cell transplant patients who have survived for at least 6 months following transplant. There are also patient versions of the guidelines that can be found at www.BeTheMatch.org/Patient (Majhail et al. 2012).

The recommendations take each system and describe the late complication and the general risk factors for developing them. It goes on to suggest the monitoring tests and preventative measures that should be undertaken supported by associated evidence from randomised trials and if none is available from retrospective studies or from expert opinion when no evidence exists at all (Majhail et al. 2012).

Infection and revaccination are described elsewhere in this textbook, but regardless of time since transplant, all presentations of infection should be thoroughly and rigorously investigated and treated aggressively. Revaccination should be initiated as per the widely accepted Tomblyn et al., (2009) guidelines.

Majhail et al. (2012) elegantly describe the general follow-up that a transplant patient should receive in a systematic order and this can be 
applied fairly easily in the clinic environment. Below is a concise form of the guidance. Please refer to Table 14.3 for the recommended screening guidelines and the full publication for further details.

\subsubsection{Ocular Screening}

Ocular screening should commence at 6 months and continue on an annual basis for assessment of keratoconjunctivitis sicca syndrome, cataracts and ischaemic microvascular retinopathy. Sicca syndrome (vaginitis, dry skin and xerostomia) occur in $10-40 \%$ of patients.

\subsubsection{Oral Examination}

The oral cavity can be affected with chronic graft versus host disease (cGvHD) and, even in the absence of cGvHD, requires repeated assessment from 6 months especially if there is a sign of xerostomia (dry mouth) as this increases the risk of dental caries. Good oral hygiene and treatment of oral infections should be initiated promptly on recognition. There is an increased risk of secondary oral squamous cell carcinoma in those with oral cGvHD, and patients should be aware to raise concerns.

\subsubsection{Pulmonary Screening}

Respiratory problems include bronchiolitis obliterans syndrome (BOS), idiopathic pneumonia syndrome (also known as interstitial pneumonitis), cryptogenic organising pneumonia (COP) and sinopulmonary infections. Clinical review at 6 months and annually with physical examination and history should be performed. Counselling with regard to smoking cessation is extremely important. If the patient has GvHD, then it may be appropriate to undertake pulmonary function testing, and if there is evidence of lung involvement, then imaging such as inspiratory and expiratory $\mathrm{CT}$ for air trapping to exclude $\mathrm{BOS}$ is indicated.
Table 14.3 Recommended screening and prevention (Majhail et al. 2012) printed with permission from Elsevier Inc

\begin{tabular}{|c|c|c|c|}
\hline $\begin{array}{l}\text { Recommended screening/ } \\
\text { prevention }\end{array}$ & $\begin{array}{l}6 \\
\text { months }\end{array}$ & $\begin{array}{l}1 \\
\text { year }\end{array}$ & Annually \\
\hline \multicolumn{4}{|l|}{ Immunity } \\
\hline $\begin{array}{l}\text { Encapsulated organism } \\
\text { prophylaxis }\end{array}$ & 2 & 2 & 2 \\
\hline PCP prophylaxis & 1 & 2 & 2 \\
\hline CMV testing & 2 & 2 & 2 \\
\hline Immunisations & 1 & 1 & 1 \\
\hline \multicolumn{4}{|l|}{ Ocular } \\
\hline $\begin{array}{l}\text { Ocular clinical symptom } \\
\text { evaluation }\end{array}$ & 1 & 1 & 1 \\
\hline Ocular fundus exam & + & 1 & + \\
\hline \multicolumn{4}{|l|}{ Oral complications } \\
\hline Clinical assessment & 1 & 1 & 1 \\
\hline Dental assessment & + & 1 & 1 \\
\hline \multicolumn{4}{|l|}{ Respiratory } \\
\hline $\begin{array}{l}\text { Clinical pulmonary } \\
\text { assessment }\end{array}$ & 1 & 1 & 1 \\
\hline $\begin{array}{l}\text { Smoking tobacco } \\
\text { avoidance }\end{array}$ & 1 & 1 & 1 \\
\hline Pulmonary function testing & + & + & + \\
\hline Chest radiography & + & + & + \\
\hline \multicolumn{4}{|l|}{ Cardiovascular } \\
\hline $\begin{array}{l}\text { Cardiovascular risk-factor } \\
\text { assessment }\end{array}$ & + & 1 & 1 \\
\hline \multicolumn{4}{|l|}{ Liver } \\
\hline Liver function testing & 1 & 1 & + \\
\hline Serum ferritin testing & & 1 & + \\
\hline \multicolumn{4}{|l|}{ Kidney } \\
\hline Blood pressure screening & 1 & 1 & 1 \\
\hline Urine protein screening & 1 & 1 & 1 \\
\hline BUN/creatinine testing & 1 & 1 & 1 \\
\hline \multicolumn{4}{|l|}{ Muscle and connective tissue } \\
\hline $\begin{array}{l}\text { Evaluation for muscle } \\
\text { weakness }\end{array}$ & 2 & 2 & 2 \\
\hline $\begin{array}{l}\text { Physical activity } \\
\text { counselling }\end{array}$ & 1 & 1 & 1 \\
\hline \multicolumn{4}{|l|}{ Skeletal } \\
\hline $\begin{array}{l}\text { Bone density testing (adult } \\
\text { women, all allogeneic } \\
\text { transplantation recipients } \\
\text { and patients at high risk } \\
\text { for bone loss) }\end{array}$ & & 1 & + \\
\hline \multicolumn{4}{|l|}{ Nervous system } \\
\hline $\begin{array}{l}\text { Neurologic clinical } \\
\text { evaluation }\end{array}$ & + & 1 & 1 \\
\hline $\begin{array}{l}\text { Evaluate for cognitive } \\
\text { development }\end{array}$ & & 1 & 1 \\
\hline Endocrine & & & \\
\hline
\end{tabular}

(continued) 
Table 14.3 (continued)

\begin{tabular}{|c|c|c|c|}
\hline $\begin{array}{l}\text { Recommended screening/ } \\
\text { prevention }\end{array}$ & $\begin{array}{l}6 \\
\text { months }\end{array}$ & $\begin{array}{l}1 \\
\text { year }\end{array}$ & Annually \\
\hline Thyroid function testing & & 1 & 1 \\
\hline $\begin{array}{l}\text { Growth velocity in } \\
\text { children }\end{array}$ & & 1 & 1 \\
\hline $\begin{array}{l}\text { Gonadal function } \\
\text { assessment (pre-pubertal } \\
\text { men and women) }\end{array}$ & 1 & 1 & 1 \\
\hline $\begin{array}{l}\text { Gonadal function } \\
\text { assessment (post-pubertal } \\
\text { women) }\end{array}$ & & 1 & + \\
\hline $\begin{array}{l}\text { Gonadal function } \\
\text { assessment (post-pubertal } \\
\text { men) }\end{array}$ & & + & + \\
\hline \multicolumn{4}{|l|}{ Mucocutaneous } \\
\hline $\begin{array}{l}\text { Skin self-exam and sun } \\
\text { exposure counselling }\end{array}$ & 1 & 1 & 1 \\
\hline $\begin{array}{l}\text { Gynaecologic exam in } \\
\text { women }\end{array}$ & + & 1 & 1 \\
\hline \multicolumn{4}{|l|}{ Second cancers } \\
\hline $\begin{array}{l}\text { Second cancer vigilance } \\
\text { counselling }\end{array}$ & & 1 & 1 \\
\hline $\begin{array}{l}\text { Screening for second } \\
\text { cancers }\end{array}$ & & 1 & 1 \\
\hline \multicolumn{4}{|l|}{ Psychosocial } \\
\hline $\begin{array}{l}\text { Psychosocial/QOL clinical } \\
\text { assessment }\end{array}$ & 1 & 1 & 1 \\
\hline Sexual function assessment & 1 & 1 & 1 \\
\hline \multicolumn{4}{|c|}{$\begin{array}{l}\text { Majhail et al. (2012) } \\
1 \text { recommended for all transplantation recipients, } 2 \text { rec- } \\
\text { ommended for any patient with ongoing cGvHD or } \\
\text { immunosuppression, + reassessment recommended for } \\
\text { abnormal testing in a previous time period or for new } \\
\text { signs/symptoms }\end{array}$} \\
\hline
\end{tabular}

\subsubsection{Cardiovascular Tests}

Cardiovascular disease is rare in the transplant setting. Clinical review at 6 months and annually with physical examination, blood pressure monitoring and history should be performed. Counselling with regard to a healthy lifestyle, taking regular exercise, maintaining a healthy weight, eating well and not smoking should be reinforced in clinic and be in line with the recommendations for the general public. Risk factors such as diabetes, hypertension and dyslipidaemia can be addressed with non-medication interventions, but some may require treatment if this approach is unsuccessful. If any concerns are raised, investigations with ECG and ECHO and referral to cardiology may be needed.

\subsubsection{Hepatic Complications}

Liver function tests are taken at most clinical reviews and aid assessing for the onset of GvHD. Patients with pre-existing liver conditions such as hepatitis $\mathrm{B}$ or $\mathrm{C}$ should have monitoring of their viral load by polymerase chain reaction (PCR) and referral to a hepatologist or virologist for advice on ongoing antiviral therapy. Serum ferritin levels should be measured at 1 year, and those with elevated levels should be followed more closely and considered for chelation.

\subsubsection{Renal Surveillance}

Renal injury is common post-transplant as many drugs are nephrotoxic such as ciclosporin, aminoglycosides, acyclovir, etc., and renal function should be checked at 6 months and annually thereafter. In those with chronic kidney disease (CKD), referral to nephrology and assessment with renal ultrasound and/or biopsy should be considered.

\subsubsection{Musculoskeletal Assessment}

Patients with GvHD and especially those receiving systemic steroids may encounter problems with muscle strength, general weakness and loss of function. All patients should be given advice about regular daily exercise. Those who have developed GvHD should be assessed for range of joint movement to detect sclerotic changes and referred on to physiotherapy for active intervention.

Osteoporosis is common with reports of incidence of $25-50 \%$ at 18 months (Majhail et al. 2012). Those with ongoing GvHD requiring long-term use of corticosteroids are at particular risk. DEXA scanning is indicated and advice regarding diet and exercise given to optimise bone mineral density and falls prevention. Supplementation with vitamin D and calcium may be required. 


\subsubsection{Neurological Assessment}

All patients should be assessed annually for signs and symptoms of neurologic deficit such as leukoencephalopathy, cognitive impairment or neurotoxicity as a consequence of long-term use of calcineurin inhibitors. Also any signs or symptoms of peripheral neuropathy should be examined for. If any deficit is found during routine assessment, the patient should be referred for nerve conduction studies or MRI as indicated by the clinical findings. A referral to a neurologist may be appropriate.

\subsubsection{Endocrine Surveillance}

Endocrine dysfunction is common following stem cell transplant. Thyroid function and gonadal testing are recommended at 1 year and then annually with replacement if needed. Up to $25 \%$ of patients who receive total body irradiation will have some thyroid dysfunction (Majhail et al. 2012). Significant gonadal failure requiring hormone replacement is more common in women than men as the ovaries are more sensitive to the effects of chemoradiotherapy than the testes. Sexual dysfunction and assessment of sexual function are described more fully in this chapter. Sexual dysfunction is common although typically under-reported and results in impaired quality of life (QoL) and relationship problems.

\subsubsection{Second Malignancy Screening}

All patients should be counselled regarding the increased risk of secondary cancers and advised to monitor themselves frequently (breast and testicular examination) and report symptoms promptly. The median time to development is 5-6 years post-therapy although this risk continues to rise with no plateau. Cancers of all organs are well described but the skin, oral cavity, CNS, bone, thyroid and connective tissue are more prevalent. Breast screening should be carried out for women who receive total body irradiation at age 25 or 8 years following exposure whichever is later but no later than 40 years. Cervical PAP smears should be performed every 1-3 years (yearly if presence of GvHD) in women aged 21 and over or within 3 years of initial sexual activity whichever is earliest. Advice regarding sun exposure, wearing sun screen, loose fitting clothing and a hat and glasses when outside should be given to all patients.

\subsubsection{Psychological Screening}

Psychological problems may manifest in various ways in the post-transplant setting, and clinicians need to be vigilant for subtle signs and make appropriate referrals for interventions. Depression, anxiety, fatigue and psychosexual dysfunction are frequently observed. This often increases in the transition from early transplant recovery to longer-term follow-up as the patient adjusts to the change in life style, employment and financial independence. Relationships with family and friends may change leading to distressing outcomes. A low level of suspicion should be maintained by the clinician for early signs of psychological distress throughout follow-up.

\subsubsection{Fertility Concerns}

Fertility is often lost due to high-dose treatments although not in all. Patients should be counselled thoroughly regarding safe sex in those of childbearing age. Those who are contemplating pregnancy should be referred on to specialist services for advice and monitoring.

\subsubsection{Summary}

There is no standard instrument guiding posttransplant care that will apply to all patients who have undergone stem cell transplant. Each patient is an individual, and, as such, an individualised plan needs to be generated. Large institutions have published guidelines, such as Fred 
Hutchinson Cancer Research Center's LTFU guidelines, the National Marrow Donor Program Be The Match long-term survival guidelines, the Livestrong Care Plan and the Passport for Cure, to name but a few.

The key message is that early screening leads to early detection and treatment, although it is not fully proven that this leads to better outcomes. It is the role of all healthcare providers to raise awareness for the potential for secondary effects of high-dose therapies and to ensure adequate and appropriate survivorship care. Empowering patients to be involved in their own long-term care is paramount. Having 'buy-in' from the patient will help to ensure that they are vigilant for subtle changes and attend screening appointments. They have self-interest at heart and are unlikely to forget that they require certain followup tests if they are educated in the late effects clinic. As they enter a passive watchful and waiting period, this is the time when things can be forgotten, so vigilance from the patient and family will help the clinical team avoid errors and omissions.

Having a written care plan or treatment summary detailing the chemotherapies, radiation and side effects suffered with future dates for screening is ideal and can be based on any of the published material listed above. Educate the patient and family on the new normal, what can be expected and when, enable them to become an active participant in their own post-transplant care and help our patients navigate the potentially stormy waters ahead.

\subsection{Metabolic Syndrome}

In addition to the more familiar post-HSCT sequelae, metabolic syndrome (MetS) is of particular note due to its collection of cardiovascular risk factors that increase the risk of cardiovascular disease, diabetes mellitus and all-cause mortality. Long-term survivors of HSCT have a considerable risk of developing MetS and subsequently cardiovascular disease. The estimated prevalence of MetS is $31-49 \%$ among HSCT recipients.
A series of recommendations (Table 14.4) have been developed (DeFilipp et al. 2016) to help clinicians provide screening and preventive care for MetS and cardiovascular disease among HSCT recipients. Furthermore, all HSCT survivors should be advised of the risks of MetS and encouraged to undergo the recommended screening based on their predisposition and ongoing risk factors.

\subsection{Compliance and Adherence in the Long-Term Follow-Up Setting}

Compliance and adherence issues are common in HSCT survivors. Reasons given in the literature for refusal, noncompliance or abandonment of treatment include the patient's physical discomfort, misunderstanding and uncertainty about the merits of medication, poor communication regarding the diagnosis and treatment regime and inadequate information on illness in general and secondary effects of the disease and its treatment in particular.

Five factors of adherence (WHO 2003):

1. Health system

2. Socio-economic

3. Health or condition

4. Treatment

5. Patient

1. Health System

A relationship based on a partnership between the patient, relatives and the treating physician improves adherence (Russmann et al. 2010). Insufficient and inadequate doctor/patient/family dialogue, relationship, trust and mutual information are quoted as one of the most important causes of noncompliance.

Poor attention to patient education with regard to medication benefits and risks, side effects and correct dosing can result in decreased quality of life, more frequent consultations and possible hospital readmissions. 


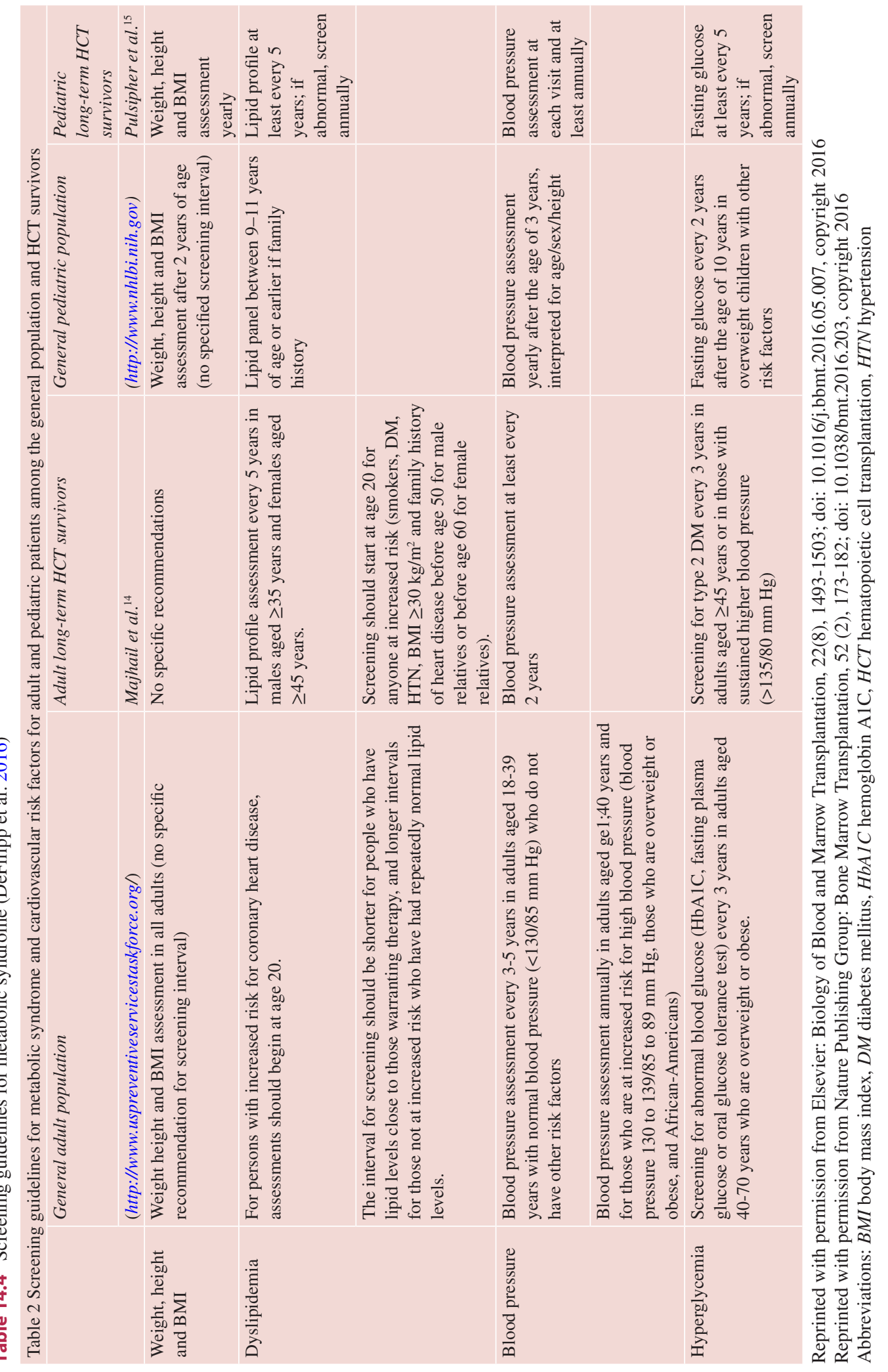


A whole team approach to education and support facilitates the development of joint strategies that increase likelihood of adherence.

\section{Socio-economic}

Reasons for noncompliance may revolve around a lack of resources, both in the patient's finances and in the level of clinical expertise and medical facilities available.

The economic cost of cancer plays a significant role in therapy adherence. Many patients need to travel considerable distances to access treatment at substantial personal cost. Furthermore, the majority of patients and many of their carers are unable to work during and for many months following treatment leading to a loss of income and a lack of financial stability.

Availability of social support services is yet another potent factor, especially in patients overwhelmed by multiple pressing needs.

3. Health or Condition

Extensive symptoms such as nausea, vomiting, pain, constipation and fatigue play an important role in a person's ability to manage medication and follow a treatment course with a degree of reliability.

Disease progression and declining health can interfere with the physical ability to manage treatment and also the willingness to continue with treatment.

4. Treatment

Therapy-related factors refer to the treatment regime and the process of taking medication according to the regime. To optimise compliance requires precision and concentration and the ability to follow specific instructions around timing of dosing. Often careful planning around the daily programme of treatment will increase the patient's ability to follow the treatment plan accurately.

Drug frequency, odour, side effects and prior experience of therapy can all impact upon and hinder compliance (Lee et al. 1992).

5. Patient

The patient's attitude towards their illness and treatment are important factors. Their support network, resources, disease knowl- edge, health beliefs and expectations are central to the degree to which they will be able to follow treatment.

Psychological distress or other psychological factors may also be a cause of poor compliance, often requiring professional intervention and support.

For many patients, a simple lack of understanding of the importance of regular treatment or assessment is the driver for poor adherence or attendance. Others are afraid that annual check-ups may reveal sinister pathology that they would prefer to ignore.

\subsection{Immunisations Following Stem Cell Transplantation}

Stem cell transplant recipients have a reduction in their antibody levels or titres to vaccinepreventable diseases. This ranges from $50 \%$ to $75 \%$ loss of cover for tetanus, diphtheria, polio, $S$. pneumoniae and $H$. influenzae at 1 year, rising to $100 \%$ loss of protection at 2 years in the nonrevaccinated patient Ljungman et al., (2009). This may occur in both autologous and allogeneic stem cell transplant patients having peripheral blood, umbilical cord blood or bone marrow transplantation. Therefore, all stem cell transplant recipients should be routinely revaccinated (Tables 14.5 and 14.6). As limited data exists in alternative donor settings of cord and haplo-identical transplant, the guidelines suggest that for simplicity the same revaccination schedule should be followed for all stem cell transplant patients until further evidence is generated (Ljungman et al. 2009).

There may be some immune function derived from the donated stem cells, but this is unreliable and as such post-transplant vaccine should be used (Johnston and Conly, 2002).

For those patients who develop chronic graft versus host disease (cGvHD), it is likely that all immune function and protection are lost and Ljungman et al. (2009) recommend the same revaccination schedule but advocate measuring antibody levels pre- and post-vaccine to deter- 
Table 14.5 Vaccination of haematopoietic cell transplant recipients

\begin{tabular}{|c|c|c|c|c|}
\hline Vaccine & $\begin{array}{l}\text { Recommended for use after } \\
\text { HCT }\end{array}$ & $\begin{array}{l}\text { Time post-HCT } \\
\text { to initiate } \\
\text { vaccine }\end{array}$ & No. of doses ${ }^{a}$ & $\begin{array}{l}\text { Improved by donor } \\
\text { vaccination } \\
\text { (practicable only in } \\
\text { related-donor setting) }\end{array}$ \\
\hline $\begin{array}{l}\text { Pneumococcal conjugate } \\
\text { (PCV) }\end{array}$ & Yes (BI) & 3-6 months & $3-4^{b}$ & $\begin{array}{l}\text { Yes; may be } \\
\text { considered when the } \\
\text { recipient is at high } \\
\text { risk for chronic } \\
\text { GVHD }\end{array}$ \\
\hline $\begin{array}{l}\text { Tetanus, diphtheria, } \\
\text { acellular pertussis }\end{array}$ & $\begin{array}{l}\text { Yes } \\
\text { Tetanus-diphtheria (BII) } \\
\text { Pertussis (CIII) }\end{array}$ & $6-12$ months & $3^{\mathrm{d}}$ & $\begin{array}{l}\text { Tetanus: likely } \\
\text { Diphtheria: likely } \\
\text { Pertussis: unknown }\end{array}$ \\
\hline $\begin{array}{l}\text { Haemophilus influenzae } \\
\text { conjugate }\end{array}$ & Yes (BII) & $6-12$ months & 3 & Yes \\
\hline Meningococcal conjugate & $\begin{array}{l}\text { Follow country } \\
\text { recommendations for general } \\
\text { population }(\mathrm{BII})\end{array}$ & $6-12$ months & 1 & Unknown \\
\hline Inactivated polio & Yes (BII) & 6-12 months & 3 & Unknown \\
\hline Recombinant hepatitis B & $\begin{array}{l}\text { Follow country } \\
\text { recommendations for general } \\
\text { population }(\mathrm{BII})\end{array}$ & $6-12$ months & 3 & Likely $^{\mathrm{e}}$ \\
\hline Inactivated influenza & Yearly (AII) & 4-6 months & $1-2^{\mathrm{f}}$ & Unknown \\
\hline $\begin{array}{l}\text { Measles-Mumps-Rubella } \\
\text { (live) }\end{array}$ & $\begin{array}{l}\text { Measles: All children and } \\
\text { seronegative adults Measles: } \\
\text { BII } \\
\text { Mumps: CIII } \\
\text { Rubella: BIII } \\
\text { EIII (<24 months post-HCT, } \\
\text { active GVHD, on immune } \\
\text { suppression) }\end{array}$ & 24 months & $1-2^{\mathrm{h}}$ & Unknown \\
\hline
\end{tabular}

Ljungman et al., (2009)

Reprinted with permission from Macmillan Publishers Ltd: Bone Marrow Transplantation, 44, 521-526; doi:10.1038/ bmt.2009.263, copyright 2009

Vaccinations recommended for both autologous and allogeneic HCT recipients

Abbreviations: DtaP diphtheria tetanus pertussis vaccine, $H C T$ haematopoietic cell transplant, $P C V$ pneumococcal conjugate vaccine, Tdap tetanus toxoid-reduced diphtheria toxoid-reduced acellular pertussis vaccine

${ }^{a}$ A uniform-specific interval between doses cannot be recommended, as various intervals have been used in studies. As a general guideline, a minimum of 1 month between doses may be reasonable

${ }^{b}$ Following the primary series of three PCV doses, a dose of the 23-valent polysaccharide pneumococcal vaccine (PPSV23) to broaden the immune response might be given (BII). For patients with chronic GVHD who are likely to respond poorly to PPSV23, a fourth dose of the PCV should be considered instead of PPSV23 (CIII)

'DTaP is preferred; however, if only Tdap is available (e.g. because DTaP is not licensed for adults), administer Tdap. Acellular pertussis vaccine is preferred, but the whole-cell pertussis vaccine should be used if it is the only pertussis vaccine available (see text for more information)

${ }^{\mathrm{d}}$ See text for consideration of an additional dose(s) of Tdap for older children and adults

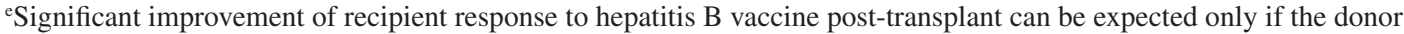
receives more than one hepatitis vaccine dose before donation

${ }^{\mathrm{f}}$ For children $<9$ years of age, two doses are recommended yearly between transplant and 9 years of age ${ }^{306}$

${ }^{\mathrm{g}}$ Measles, mumps and rubella vaccines are usually given together as a combination vaccine. In females with pregnancy potential, vaccination with rubella vaccine either as a single or a combination vaccine is indicated

hIn children, two doses are favoured 
Table 14.6 Vaccination of haematopoietic cell transplant recipients

\begin{tabular}{|c|c|c|}
\hline Vaccine & Recommendations for use & Rating \\
\hline \multicolumn{3}{|l|}{ Optional } \\
\hline Hepatitis A & $\begin{array}{l}\text { Follow recommendations for general } \\
\text { population in each country } \\
\text { Ig should be administered to hepatitis } \\
\text { A-susceptible HCT recipients who } \\
\text { anticipate hepatitis A exposure (for } \\
\text { example, during travel to endemic } \\
\text { areas) and for post-exposure } \\
\text { prophylaxis }\end{array}$ & CIII \\
\hline Varicella (Varivax, live) & $\begin{array}{l}\text { Limited data regarding safety and } \\
\text { efficacy }\end{array}$ & $\begin{array}{l}\text { EIII ( }<24 \text { months post-HCT, active } \\
\text { GVHD or on immunosuppression) } \\
\text { CIII ( }>24 \text { months, without active GVHD } \\
\text { or on immunosuppression) }\end{array}$ \\
\hline Human papillomavirus & $\begin{array}{l}\text { Follow recommendations for general } \\
\text { population in each country } \\
\text { No data exist regarding the time after } \\
\text { HCT when vaccination can be } \\
\text { expected to induce an immune } \\
\text { response }\end{array}$ & CIII \\
\hline Yellow fever (live) & $\begin{array}{l}\text { Limited data regarding safety and } \\
\text { efficacy } \\
\text { The risk-benefit balance may favour } \\
\text { the use of the vaccine in patients } \\
\text { residing in or travelling to endemic } \\
\text { areas }\end{array}$ & $\begin{array}{l}\text { EIII ( }<24 \text { months, active GVHD or on } \\
\text { immunosuppression) } \\
\text { CIII ( }>24 \text { months, without active GVHD } \\
\text { or on immunosuppression) }\end{array}$ \\
\hline Rabies & 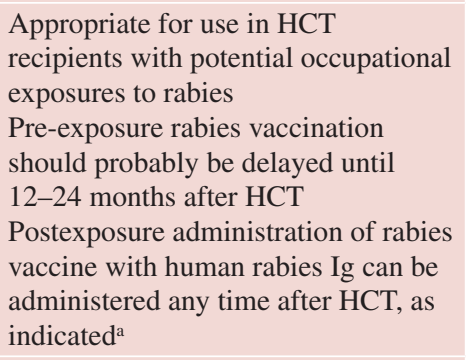 & CIII \\
\hline Tick-borne encephalitis (TBE) & $\begin{array}{l}\text { According to local policy in endemic } \\
\text { areas } \\
\text { No data exist regarding the time after } \\
\text { HCT when vaccination can be } \\
\text { expected to induce an immune } \\
\text { response }\end{array}$ & CIII \\
\hline Japanese B encephalitis & $\begin{array}{l}\text { According to local policy when } \\
\text { residing in or travelling to endemic } \\
\text { areas } \\
\text { No data exist regarding the time after } \\
\text { HCT when vaccination can be } \\
\text { expected to induce an immune } \\
\text { response }\end{array}$ & CIII \\
\hline \multicolumn{3}{|l|}{ Not recommended } \\
\hline Bacillus Calmette-Guérin (live) & Contraindicated for HCT recipients & EII \\
\hline Oral poliovirus vaccine (live) & $\begin{array}{l}\text { Should not be given to } \mathrm{HCT} \\
\text { recipients, as an effective, inactivated } \\
\text { alternative exist }\end{array}$ & EIII \\
\hline
\end{tabular}


Table 14.6 (continued)

\begin{tabular}{|c|c|c|}
\hline $\begin{array}{l}\text { Intranasal influenza } \\
\text { vaccine (live) }\end{array}$ & $\begin{array}{l}\text { No data regarding safety and } \\
\text { immunogenicity } \\
\text { Should not be given to HCT } \\
\text { recipients, as an effective, inactivated } \\
\text { alternative exist }\end{array}$ & EIII \\
\hline Cholera & $\begin{array}{l}\text { No data were found regarding safety } \\
\text { and immunogenicity among HCT } \\
\text { recipients }\end{array}$ & DIII \\
\hline Typhoid, oral (live) & $\begin{array}{l}\text { No data were found regarding safety } \\
\text { and immunogenicity among HCT } \\
\text { recipients }\end{array}$ & EIII \\
\hline Typhoid (i.m.) & $\begin{array}{l}\text { No data were found regarding safety, } \\
\text { immunogenicity or efficacy among } \\
\text { HCT recipients }\end{array}$ & DIII \\
\hline Rotavirus & $\begin{array}{l}\text { Must be given before } 12 \text { weeks of } \\
\text { age to be safe }\end{array}$ & EIII \\
\hline Zoster vaccine (Zostavax, live) & $\begin{array}{l}\text { No data regarding safety among HCT } \\
\text { recipients }\end{array}$ & EIII \\
\hline
\end{tabular}

Ljungman et al., (2009)

Reprinted withby permission from Macmillan Publishers Ltd: Bone Marrow Transplantation, 44, 521-526; doi:10.1038/ bmt.2009.263, copyright 2009

Vaccinations considered optional or not recommended for both autologous and allogeneic HCT recipients Abbreviation: HCT haematopoietic cell transplant

${ }^{a}$ Current Advisory Committee on Immunisation Practices (ACIP) and American Academy of Pediatrics guidelines for post-exposure human rabies Ig and vaccine administration should be followed, which include administering five doses of rabies vaccine administered on days $0,3,7,14$ and 28 post-exposure

mine the level of cover that has been achieved and the need for any boosters.

Following transplant, patients will have specific predisposition to some opportunistic or community-acquired infections such as $S$. pneumoniae, $H$. influenzae, measles, varicella or influenza and will have a normal predisposition of contracting regular pathogens such as tetanus, polio or diphtheria. Patients are susceptible to these organisms for a variety of reasons, poor antibody levels, low CD4 and concurrent immunosuppression especially corticosteroid use in the presence of GvHD (Flowers et al., 2015).

There is good evidence that having a low antibody level to vaccine-preventable disease posttransplant and the occurrence of encapsulated bacterial infection such as $S$. pneumoniae and $H$. influenzae are linked which further bolsters the need to have vaccines.

The benefits of revaccination are twofold:
- It directly aids the individual.

- It contributes to a 'herd effect' by maintaining cover within the community.

Live vaccines that are theoretically contraindicated post-transplant are BCG, smallpox, VZV, yellow fever, oral polio and typhoid. Ljungman et al. (1995) published limited data for administration of MMR at 2 years post-transplant in children with no GvHD and who were not on any immunosuppression. They recorded a response rate for those who were seronegative of $65-75 \%$. It is generally accepted that patients who are 2 years post-transplant and at least 1 year from receiving any immunosuppression are able to receive MMR vaccine.

Family members should continue to have all of their routine vaccinations. It is suggested that inactivated polio vaccine is used in family members. If this is not possible, then isolation and 
avoidance of patient and family member (usually a child) for 4 to 6 weeks are recommended as the live virus may be shed for this time period in body fluids (saliva, vomit, urine, faeces, etc.). If this is not possible, then strict hand hygiene needs to be applied with regard to faeces (nappies or diapers) and avoidance of saliva and shared utensils to reduce risk of transmission (Tomblyn et al. 2009).

Separate guidelines initially existed and were developed by EBMT and the CDC, the IDSA and ASBMT. In order to amalgamate all of the recommendations, an expert group convened in 2009 and produced guidelines for preventing infectious complications among HSCT recipients: a global perspective. From this group, a schedule for revaccination has been agreed as laid out in these two tables and is the adopted practice in most major centres across the world.

\subsection{End-of-Life Care in the Haematopoietic Stem Cell Transplant (HSCT) Setting}

\subsubsection{Background}

The famous German philosopher Martin Heidegger once wrote that every human being is a person who is moving towards their own death. Rather than seeing this as something negative, Heidegger suggests that if we truly acknowledge that reality, then it sets us free to live life as we truly want. For many nurses working in the field of HSCT, Heidegger's call to live life to the full is often the driving force in delivering person-centred care and helping people to recover or to live well until they die.

Amidst the great advances in HSCT including increasing cure rates, people living longer and better management of toxicities, the reality still remains that some people will die of their advancing disease and/or treatment-related factors. While the majority of the patients will return home to continue living their lives, some of the adults and children cared for in this setting may die, while a patient within the hospital or be discharged home to die. In the highly clinical and technical setting of HSCT, this reality can sometimes be overlooked and avoided leaving the patient and family feeling abandoned and alone. In a study exploring the experience of living with advanced cancer, some participants spoke of feeling misunderstood and left alone with their advanced disease, a large part of their suffering and distress arose from the interpretation of their personal pain that was not easily visible to others, and many participants felt that often people did not fully understand what they were going through, leaving them feeling ultimately alone (Quinn 2011).

In reality, the delivery of good end-of-life care can be achieved through each member of the HSCT team (clinical and non-clinical), who have often got to know the patient over a prolonged period of time recognising their important role in supporting patients and their families at this time in their lives. When curative treatment is no longer an option and the focus moves to compassionate care and addressing symptoms, the trusting relationship between the patient, family and the HSCT team is crucial.

\subsubsection{End-of-Life Care}

End-of-life care and care of the dying have been defined as care that helps all those with advanced, progressive, incurable illness to live as well as possible until the day they die (GMC 2007). Unfortunately, in many parts of the world including some healthcare and HSCT settings, the team may find it difficult to discuss the reality of dying due to a lack of exposure, avoidance, fear of upsetting the patient and sometimes the overmedicalisation and over-specialisation of caring for those who are dying. In reality, care for those moving towards the end of life in the HSCT setting calls for a combination of clinical and human skills, built on sensitivity and humility, coupled 
with good symptom management - core values of nursing care.

Things have improved, but the challenge remains with some nurses and medical staff in the HSCT setting still reluctant to have a conversation about the reality that the treatment is no longer working and exploring what the patient and family would like as they approach the end of life. This may be a result of living in a society that tends to distance itself from this sensitive subject, coupled with a fear of upsetting people with what is indeed a very sensitive but human subject that, as Heidegger says, touches us all.

The following principles of good end-of-life care or commitments to those moving towards the end of life are worth considering in the HSCT setting:

- When you are moving towards the end of life, we will be honest with you and sensitively support you and your family to ensure your needs and wishes are met, and you are enabled to die in your preferred place of care.

- When you are approaching the end of your life, we will offer you the opportunity to be involved in your care planning. This will include an assessment of your needs and preferences and an agreed set of actions reflecting these choices.

- We will work to ensure that you and your family receive excellent care in accordance with your wishes, at all times of day and night. We will work with our community partners to ensure this happens.

- We will offer you personalised care, based on your wishes and needs. This will include attending to your physical, social, emotional, spiritual and religious needs.

- We recognise the importance of your family, your friends and your support network, and they have the right to have their own needs assessed and reviewed and to have a carer's plan.

- In order to care for you and your family, we will ensure that all staff and volunteers working in our team are aware of the issues surrounding care at the end of life, in particular the importance of excellence in communicating.

- We will participate in research in order to improve patient and family care at the end of life in the HSCT setting.

This commitment from the HSCT team relies on identifying when a patient may have incurable disease and/or untreatable complications, having the courage to sensitively broach the subject of dying with the patient and family, working with the patient and family to identify and address their physical, social emotional and spiritual needs and planning care together. These core principles will enable nurses, doctors and the HSCT team to support the person to receive, the right care, in the right place, at the right time, every time (GSF 2016).

\subsubsection{Caring for Those Who Are Dying}

Caring for those who are dying to identify their needs, beliefs and values requires taking the time to hear what they need to say, a process that has been described as an art (Table 14.7).

All nurses and doctors working in HSCT will be required to use the principles of palliative or supportive care in their care of those with

Table 14.7 The art of assessment (Quinn 2014)

Paying attention to the person and hearing their priorities

Thinking beyond the symptom to how it affects the person

Creating time and being present

Cocreating a plan of care with the person and family

Applying 'skilled companionship'a

Intervening and reviewing to monitor symptom support and management

a Skilled companionship has been described by Alastair Campbell (1984) as the ability to use our clinical skills as nurses and doctors and our humanity to support a person as they strive to cope with the reality of living with advanced disease. 
Table 14.8 Principles of palliative/supportive care

Providing relief from pain and other distressing symptoms

Intention not to hasten or postpone death

Integrating the physical, psychosocial and spiritual needs of patients and family

Offering a support system to support the family before and after death

Using a team approach including counselling and chaplaincy

Improving quality of life

Directing treatment, preventing unnecessary and distressing tests or treatments

Supporting the HSCT team

Adapted from Watson et al. (2011)

advanced or incurable disease including the following (Table 14.8):

\subsubsection{Managing Pain and Other Symptoms}

Mindful that good end-of-life care requires the team to attend to the person and their physical, social, spiritual and emotional needs, some of the common symptoms seen in the end-of-life care setting include those seen in Table 14.9.

Pain continues to be one of the symptoms that people with advanced disease fear and yet research clearly shows that pain management is not always achieved in a consistent and a robust manner. This may be as of a result of a number of reasons including lack of knowledge around what is meant by pain, which drugs to use, the most therapeutic doses, non-pharmacological approaches and failing to understand what pain means to the individual. While pain is often classified as nociceptive, neuropathic, refractory, breakthrough, chronic or acute and this is important to consider when assessing pain and choosing treatment options, pain can also be understood as a disturbance or a disruption in personal relationships which should be considered (Table 14.4). This approach helps the HSCT team to appreciate some of the more hidden aspects of
Table 14.9 Common symptoms in end-of-life care

Pain (physical, social, emotional, spiritual) ${ }^{\mathrm{a}}$

Nausea

Vomiting

Oral problems (dryness, ulcers, mucositis) ${ }^{\mathrm{a}}$

Anorexia/cachexia

Agitation/restlessness

Diarrhoea

Excessive secretions $^{\mathrm{a}}$

Ascites

Breathlessness $^{\mathrm{a}}$

Anxiety/distress ${ }^{\mathrm{a}}$

Depression

Confusion

Feelings of loss and grief

Aloneness

Spiritual/religious abandonment ${ }^{\mathrm{a}}$

${ }^{\mathrm{a} C o m m o n l y ~ s e e n ~ i n ~ t h e ~ l a s t ~ d a y s ~ o f ~ l i f e ~}$

Table 14.10 Pain as a disturbance or disruptions in key relationships

\begin{tabular}{l|l} 
Physical pain & $\begin{array}{l}\text { A disturbance or disruption in the } \\
\text { relationship between the person and } \\
\text { their body }\end{array}$ \\
\hline Social pain & $\begin{array}{l}\text { A disturbance or disruption in the } \\
\text { relationship between the person and } \\
\text { their world including their family, } \\
\text { work and society }\end{array}$ \\
\hline Emotional pain & $\begin{array}{l}\text { A disturbance or a disruption in the } \\
\text { relationship between the person and } \\
\text { their emotions or how they see } \\
\text { themselves }\end{array}$ \\
\hline Spiritual pain & $\begin{array}{l}\text { A disturbance or disruption in the } \\
\text { relationship between the person and } \\
\text { their beliefs and values }\end{array}$
\end{tabular}

Managing Advanced Cancer Pain Together - An expert guidance. MACPT (2016) http://www.macpt.eu [Accessed 13 Nov 2016]

pain and how other challenging symptoms can impact on the individual (Tables 14.9 and 14.10).

Rarely will the person's experience of pain happen in isolation from other symptoms/factors including anxiety, fear, loss, fatigue, breathlessness and the inability to sleep or eat. While pain can exacerbate a person's anxiety and their inability to sleep, the inability to sleep and worry 
can increase the personal experience of pain and make the pain harder to manage; all of these need to be considered. By taking a more personcentred approach (physical, social, emotional and spiritual) to symptom management, better control may be achieved (Fig. 14.2).

Following the principles of the WHO pain ladder (Fig. 14.3), a combination of pharmacological approaches which may include paracetamol, non-steroidal anti-inflammatories, opiates, corti-

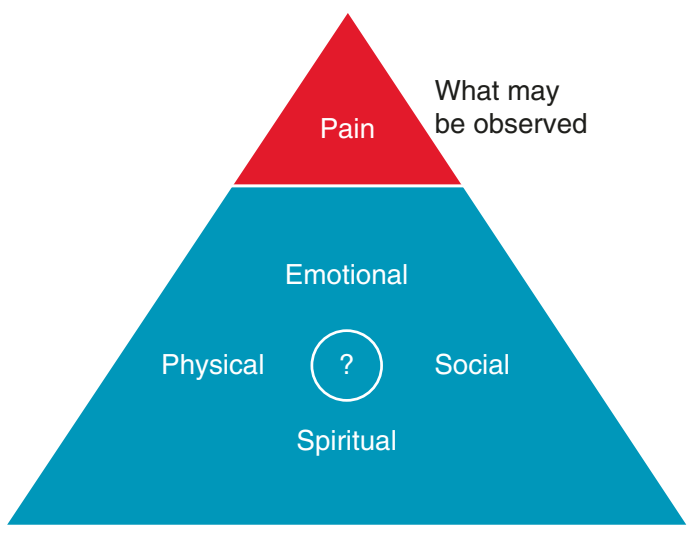

Fig. 14.2 Aspects of pain/other symptoms and what they mean to the individual are often hidden from view and take longer to identify and manage (Managing Advanced Cancer Pain Together - An expert guidance. MACPT (2016) http://www.macpt.eu [Accessed 13 Nov 2016]) costeroid, anti-depressant, anti-epileptic, antimuscarinic and benzodiazepine should be considered and reviewed and increased as required. Pain relief should be prescribed on a regular basis and prescribed as needed for "breakthrough pain'. The HSCT team should also consider the best route of administration (oral transdermal, subcutaneous, sublingual, buccal mucosa, intravenous) for the patient and derived benefit. Pharmacological approaches can be complemented with non-pharmacological interventions including massage, touch, pastoral/spiritual support, hearing the patient's concerns, music and relaxation approaches. A combination of both is often the best approach to managing total pain or indeed any symptom in advanced disease. 'To ignore psychological and spiritual aspects of care may often be the reason for seemingly intractable pain' (Watson et al. 2011. 18)

The following tool (Fig. 14.4) has been designed to encourage patients to talk about their personal experience of pain and what it means to them, but it may also be used to help the patient to talk about their experience of other symptoms. The tool is designed to invite the patient to talk about what is important to them including the reality of their own dying and their fears and concerns.
Fig. 14.3 Using the WHO approach to pain management in the HSCT setting

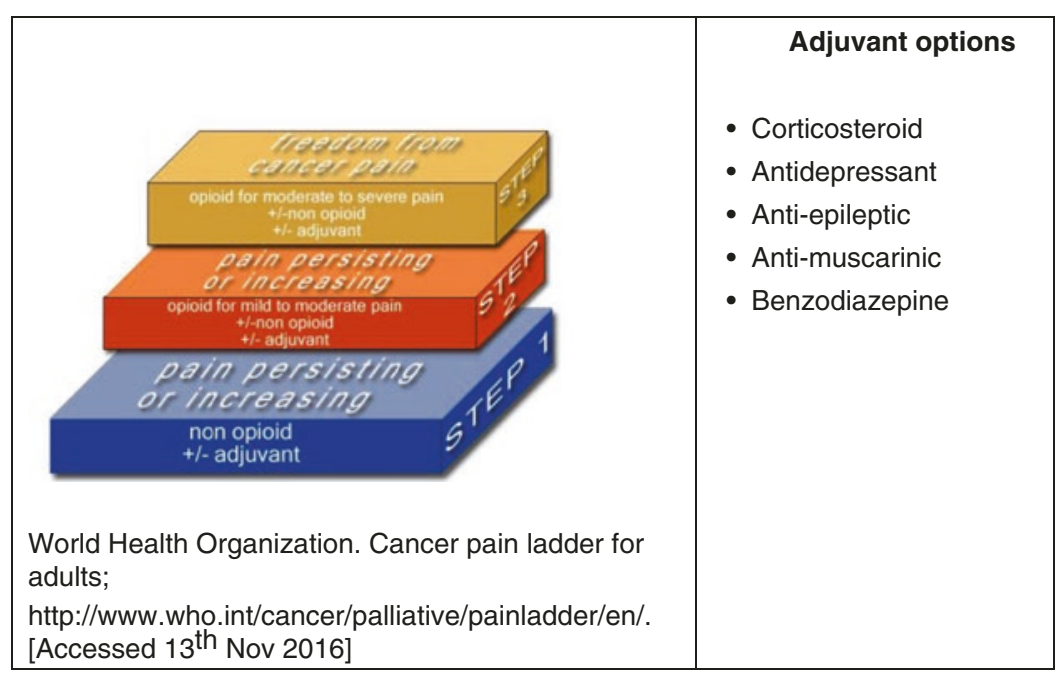




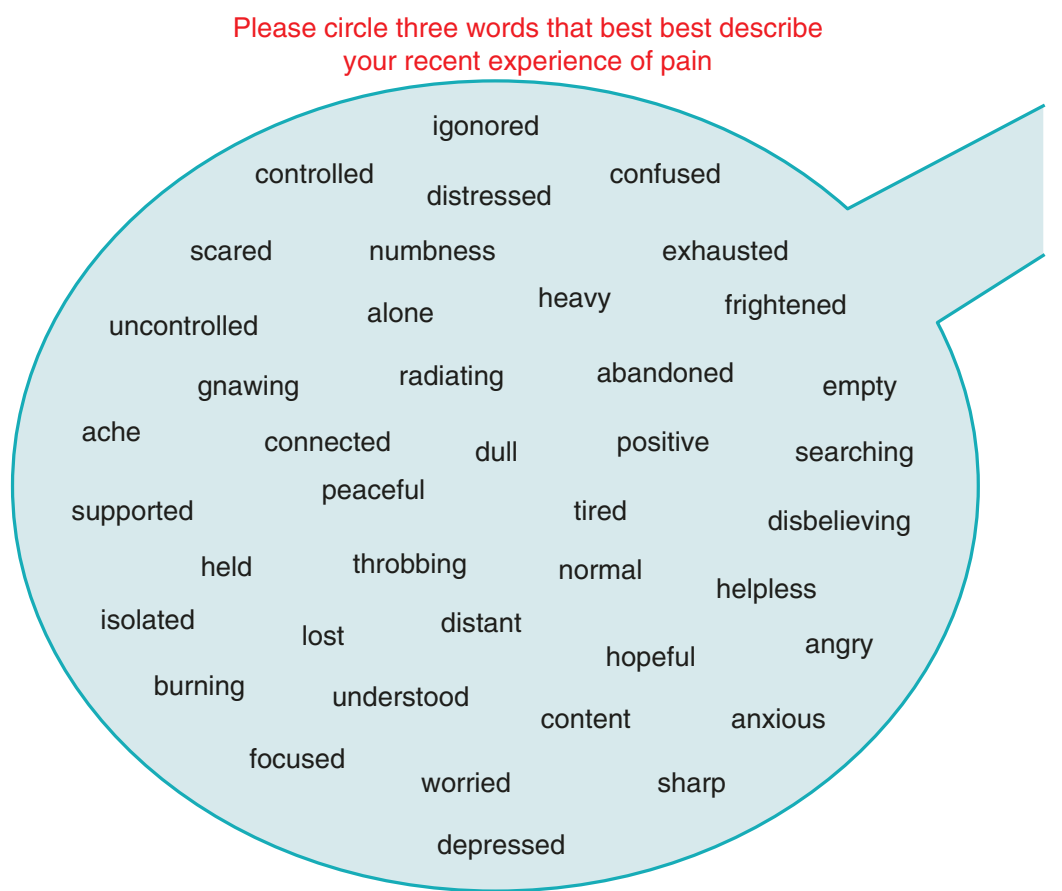

Managing Advanced Cancer Pain Together - An expert guidance. MACPT (2016). http://www.macpt.eu [Accessed 13thNov 2016].

Fig. 14.4 Everyone experiences pain differently - you might find it has an impact on your body, on your sense of well-being and how you feel about yourself, and on your relationships with others and the world around you

\subsubsection{Examples of Drugs Used in the Last Days of Life}

Pain: Morphine/diamorphine/oxycodone/alfentanil/fentanyl/Buscopan +/- adjuvant drugs

Excessive secretions: Glycopyrronium

Nausea: Levomepromazine/ondansetron/metoclopramide/cyclizine

Agitation: Midazolam

The management of other symptoms commonly seen in this setting including nausea, agitation and excessive secretions should also take both a pharmacological (Table 14.7) and nonpharmacological approach focussing on what suits the individual patient.

\subsubsection{Support}

As previously stated, an important aspect of endof-life care is recognising the HSCT team's role in supporting the patient and their family but also
(Managing Advanced Cancer Pain Together - An expert guidance. MACPT (2016). http://www.macpt.eu [Accessed 13 Nov 2016])

knowing when the person may require more expert help including pastoral care, psychological support and specialist palliative care for challenging aspects of symptom management and/or support/advice for the HSCT team. Pastoral, psychological and palliative/supportive care should be seen as a core part of HSCT care and introduced to the patient earlier so that these approaches are seen as complementing the treatment approach of HSCT. While an individual may not have any religious affiliation or religious needs, many patients will require someone to listen to their hopes and dreams, their concerns and fears. The HSCT team with careful planning, support and working with the patient's community medical and nursing team can in many cases enable patients with advanced disease to be cared for in their own home if that is the patient's wishes. While focussing on the person with advanced disease, the team is well placed to support family members including children and parents. 


\subsubsection{Conclusion}

Although the current public message appears to be one of delivering more care with less resources, this in no way negates the central focus on delivering truly holistic patient-centred care. We can no longer continue to talk about patient-centred care without a willingness to engage with all aspects of the person we support and care for including their physical, emotional, social, existential and spiritual needs. It is time to move away from a medical approach only to care in the HSCT setting to one of attending to the person. With nursing leadership and the reality of dying in the HSCT setting, there is no more urgent time to take forward the reality of person-centred care. Often the greatest gift we can give to those who are dying is our attention and presence. Amidst the uncertainty and the painful realities each person has to face, caring is often perceived as occurring when another person carries out a simple act of kindness with a caring attitude, which requires us to be attentive to them.

\subsection{Late Effects and Long-Term Follow-Up in Paediatric Patients}

The study of late effects after paediatric haematopoietic stem cell transplantation (HSCT) offers unique opportunities and challenges, magnified by the fact that children going through each developmental stage (infant, toddler, child preadolescent and young adult) have different sensitivities to therapies, resulting in different complications. For instance, infants and toddlers are susceptible to neurocognitive damage with radiation, and adolescents are at high risk of joint/bone issues with steroid therapy (Baker et al. 2011).

Paediatric HSCT survivors have a higher cumulative incidence of late effects compared to the studies of cancer survivors who did not receive HSCT as part of their treatment, with $93 \%$ of sur- vivors having at least one late effect with a median follow-up of only 7 years (Bresters et al. 2010).

Children who undergo HSCT with TBI have a significant risk of both growth hormone deficiency (GHD) and the direct effects of radiation on skeletal development. The risk is increased with single-dose TBI as opposed to fractionated TBI, pre-transplant cranial irradiation, female gender and post-treatment complications such as graft versus host disease (GVHD).

Late side effects and complications can include chronic immunosuppression and infections, chronic GvHD, bronchiolitis obliterans, endocrine dysfunction, cataracts, disease recurrence and secondary malignancies (Tomlinson and Kline 2010).

The endocrine system is highly susceptible to damage by high-dose chemotherapy and/or irradiation prior to haematopoietic stem cell transplantation (HSCT) during childhood. Insufficiency of thyroid hormone is one of the most common late sequelae of HSCT and occurs more often in young children. Deficiency in the pituitary's production of growth hormone is a problem of unique concern to the paediatric population (Dvorak et al. 2011).

\subsubsection{Specific Late Effects After HSCT in Childhood}

\subsubsection{Growth Impairment}

Impaired linear growth after HSCT is multifactorial in origin and can be due to growth hormone deficiency (GHD), hypothyroidism, hypogonadism, corticosteroid treatment as well as poor nutritional status, genetic factors and metabolic status. Because of these confounding factors, the reported prevalence of growth impairment varies widely (9-84\%) between studies (Baker et al. 2011).

Treatment includes thyroid replacement therapy and growth hormone therapy, respectively, for thyroid dysfunction and growth delays (Tomlinson and Kline 2010). 
Growth hormone deficiency (GHD) replacement therapy provides the benefit of optimising height outcomes among children who have not reached skeletal maturity (Chemaitilly and Robison 2012).

Even though myeloablative conditioning regimens for HSCT are known to affect endocrine function, Myers et al. (2016) recently evidenced that 'poor growth, thyroid dysfunction and vitamin D deficiency remain prevalent despite reduced intensity chemotherapy for haematopoietic stem cell transplantation in children and young adults'.

\subsubsection{Neurocognitive Impairment}

There is limited evidence of neurocognitive and academic outcomes in paediatric HSCT:

- HSCT seems to pose a low risk overall.

- Risk increases for children of age $<5 y$ years at the time of SCT who received TBI (Phipps et al. 2008).

The procedure of SCT entails probably minimal risk of late cognitive and academic sequelae. Subgroups of patients are at relatively higher risk: patients undergoing unrelated donor transplantation, receiving TBI and those who experience GVHD. No significant changes are seen in global intelligence quotient and academic achievement (Phipps et al. 2008).

Despite substantial exposure to potentially neurotoxic agents, studies have generally shown survivors of paediatric HSCT to be within normal limits in cognitive and academic functioning, and with stable performance over time, although children who are younger at the time of transplantation may be at increased risk for cognitive impairment (Phipps et al. 2008).

Phipps et al. (2008) reported 158 patients who survived and were evaluated at 1, 3 and 5 years' post-transplant and concluded that HSCT, even with TBI, poses low to minimal risk for late cognitive and academic deficits in patients who are at least 6 years old at the time of transplantation. However, socio-economic status was found to be a significant determinant of all cognitive and academic outcomes.

\subsubsection{Return to School}

A diagnosis of cancer during the teenage years arrives at an important stage of development, where issues of normality, identity and independence are crucial. Education provides opportunity for peer contact, achievement and development for teenagers.

Key areas involved in the impact of a cancer diagnosis on teenagers' educational engagement include school attendance, reintegration and peer relationships. Long-term school absences are a concern for teenagers but do not necessarily lead to a reduction in educational and vocational attainment. It is important to involve healthcare and education professionals, as well as parents and teenagers themselves, in school matters (Pini et al. 2012).

Factors that may place children and teens at increased risk for difficulties in school (Landier et al. 2013) include:

- Diagnosis of cancer at a very young age

- Numerous prolonged school absences

- A history of learning problems before being diagnosed with cancer

- Cancer treatment that results that reduced energy levels

- Cancer treatment that affects hearing or vision

- Cancer treatment that results in physical disabilities

- Cancer treatment that includes treatment to the central nervous system

Collaborative education planning should be initiated on diagnosis and aim to include nonacademic variables, such as peer groups, which can influence successful maintenance of education. Further research is needed to understand the relationship between education engagement and teenagers' cancer experiences as a whole, as well as gaining a more in depth understanding of how teenagers experience their education after a diagnosis of cancer (Pini et al. 2013).

It will therefore be imperative that we continue to follow our HSCT survivors on a longterm basis and continue research efforts to study long-term outcomes (Baker et al. 2011). 


\section{References}

Anderson KO, Giralt SA, Mendoza TR, Brown JO, Neumann JL, Mobley GM, Wang XS, Cleeland CS. Symptom burden in patients undergoing autologous stem-cell transplantation. Bone Marrow Transplant. 2007;39(12):759-66.

Andorsky DJ, Loberiza FR, Lee SJ. Pre-transplantation physical and mental functioning is strongly associated with self-reported recovery from stem cell transplantation. Bone Marrow Transplant. 2006;37:889-95.

Andrykowski M, Bishop M, Hahn E, Cella D, Beaumont J, Brady M, Horowitz M, Sobocinski K, Rizzo J, Wingard J. Long-term health related quality of life, growth and spiritual well-being after haematopoietic stem cell transplantation. J Clin Oncol. 2005;23:599-08.

Baker F, Zahora J, Polland A, Wingard J. Reintegration after bone marrow transplantation. Cancer Pract. 1999;7:190-7.

Baker S, Bhatia S, Bunin N, Nieder M, Dvorak C, Sung L, Sander J, Kurtzberg J, Pulsiphe M. NCI, NHLBI first international consensus conference on late effects after pediatric hematopoietic cell transplantation: state of the science, future directions. Biol Blood Marrow Transplant. 2011;17(10):1424-7.

Bhatia S, Francisco L, Carter A, Sun CL, Baker KS, Gurney JG, McGlave PB, Nademanee A, O'Donnell M, Ramsay NK, Robison LL, Snyder D, Stein A, Forman SJ, Weisdorf DJ. Late mortality after allogeneic hematopoietic cell transplantation and functional status of long-term survivors: report from the bone marrow transplant survivor study. Blood. 2009;110(10):3784-92.

Bieri S, Roosneck E, Helg C, Verholen F, Robert D, Chapius B, Passweg J, Miralbell R, Chalandon Y. Quality of life and social integration after allogeneic hematopoietic SCT. Bone Marrow Transplant. 2008;42:819-27.

Brandenburg D, Grover L, Quinn B. Intimacy and sexuality for cancer patients and their partners: PanBirmingham Cancer Psychology Services; 2010.

Bresters D, van Gils IC, Kollen WJ, Ball LM, Oostdijk W, van der Bom JG, Egeler RM. High burden of late effects after haematopoietic stem cell transplantation in childhood: a single-centre study. Bone Marrow Transplant. 2010;45(1):79-85.

Chemaitilly W, Robison LL. Safety of growth hormone treatment in patients previously treated for cancer. Endocrinol Metab Clin North Am. 2012;41(4):785-92.

Curtis RE, Rowlings PA, Deeg J, Shriner DA, Socié G, Travis LB, Horowitz MM, Witherspoon RP, Hoover RN, Sobocinski KA, Fraumeni JF, Boice JD, Gary Schoch G, Sale GE, Storb R, Travis WD, Kolb H-J, Gale RP, Passweg JR. Solid cancers after bone marrow transplantation. N Engl J Med. 1997;336:897-904.

DeFilipp Z, Duarte RF, Snowden JA, Majhail NS, Greenfield DM, Miranda JL, Arat M, Baker KS, Burns
LJ, Duncan CN, Gilleece M, Hale GA, Hamadani M, Hamilton BK, Hogan WJ, Hsu JW, Inamoto Y, Kamble RT, Lup-Stanghellini MT, Malon AK, McCarthy P, Mohty M, Norkin M, Paplham P, Ramanathan M, Richart JM, Salooja N, Schouten HC, Seber A, Steinberg A, Wirk BM, Wood WA, Battiwala M, Flowers MED, Savani BN, Shaw BE; on behalf of the CIBMTR Late Effects and Quality of Life Working Committee and the EBMT Complications and Quality of Life Working Party. Metabolic syndrome and cardiovascular disease following hematopoietic cell transplantation: screening and preventive practice recommendations from CIBMTR and EBMT. Bone Marrow Transplant. 2016:1-10.

DoH. National cancer survivorship initiative - vision. London: Crown; 2010.

Dvorak CC, Gracia CR, Sanders JE, Cheng EY, Baker KS, Pulsipher MA, Petryk A. NCI, NHLBI/PBMTC first international conference on late effects after pediatric hematopoietic cell transplantation: endocrine challenges-thyroid dysfunction, growth impairment, bone health, \& reproductive risks. Biol Blood Marrow Transplant. 2011;17(12):1725-38.

Flowers M, et al. 2015. https://www.fredhutch.org/ content/dam/public/Treatment-Suport/Long-TermFollow-Up/LTFU_HSCT_guidelines_physicians.pdf. version June 03, 2015. Accessed 22 Sept 2016.

Freidrichs B, Tichelli A, Bacigalupo A, Russell N, Ruutu T, Shapira M, Beksac M, Hasenclever D, Socie G, Schmitz N. Long-term outcome and late effects in patients transplanted with mobilised blood or bone marrow: a randomised trial. Lancet Oncol. 2010;11(4):331-8.

Gielissen M, Verhagen S, Witjes F, Bleijenberg G. Effects of cognitive behaviour therapy in severely fatigued disease-free cancer patients compared with patients waiting for cognitive behaviour therapy: a randomized controlled trial. J Clin Oncol. 2006;24:4882-8.

Hamblin A, Greenfield DM, Gilleece M, Salooja N, Kenyon M, Morris E, Glover N, Miller P, Braund H, Peniket A, Shaw BE, Snowden JA, on behalf of the British Society of Blood and Marrow Transplantation (BSBMT). Provision of long-term monitoring and late effects services following adult allogeneic haematopoietic stem cell transplant: a survey of UK NHS-based programmes. Bone Marrow Transplant. 2017;52:889-894. (June 2017). https://doi. org/10.1038/bmt.2017.67.

International Standards for Hematopoietic Cellular Therapy Product Collection, Processing, and Administration. Sixth Edition (2015) from the Federation for Accreditation of Cell Therapy (FACT) and the Joint Accreditation Committee of ISCTEurope and EBMT (JACiE). Available from: http:// www.jacie.org.

Jean CY, Syrjala KL. Sexuality after hematopoietic stem cell transplantation. Cancer J (Sudbury, Mass). 2009;15(1):57. 
Johnston BL, Conly JM. Immunization for bone marrow transplant recipients. Can J Infect Dis. 2002;13(6):353-7.

Landier W, Leonard M, Ruccione KS. Children's Oncology Group's 2013 blueprint for research: nursing discipline. Pediatr Blood Cancer. 2013;60:1031-6. https://doi.org/10.1002/pbc.24415.

Lee CR, Nicholson PW, Souhami RL, Deshmukh AA. Patient compliance with oral chemotherapy as assessed by a novel electronic technique. J Clin Oncol. 1992;10(6):1007-13.

Ljungman $\mathrm{P}$, Cordonnier C, de Bock R, Einsele H, Engelhard D, Grundy J, Link H, Locasciulli A, Prentice HG, Reusser P, Ribaud P. Immunisations after bone marrow transplantation: results of a European survey and recommendations from the infectious diseases working party of the European Group for Blood and Marrow Transplantation. Bone Marrow Transplant. 1995;15:455-60.

Ljungman P, Cordonnier C, Einsele H, Englund J, Machado CM, Storek J, Small T. Vaccination of hematopoietic cell transplant recipients. Bone Marrow Transplant. 2009;44:521-6.

Majhail NS, Rizzo JD, Lee SJ, Aijurf M, Atsuta Y, Bonfim C, Burns LJ, Chaudhri N, Davies S, Okamoto S, Seber A, Socie G, Szer J, Van Lint MT, Wingard JR, Tichelli A. Recommended screening and preventive practices for long-term survivors after hematopoietic cell transplantation. Hematol Oncol Stem Cell Ther. 2012;5(1):1-30.

Mosher CE, Redd WH, Rini CM, Burkhalter JE, DuHamel KN. Physical, psychological, and social sequelae following hematopoietic stem cell transplantation: a review of the literature. Psychooncology. 2009;18(2):113-27.

Mulhall J. Saving your sex life. Munster: Saving your Sex Life. Münster, Germany: Hilton Publication; 2008.

Murphy RF. The body silent. New York: W.W. Norton; 1990.

Myers KC, Howell JC, Wallace G, Dandoy C, El-Bietar J, Lane A, Davies SM, Jodele S, Rose SR. Poor growth, thyroid dysfunction and vitamin $\mathrm{D}$ deficiency remain prevalent despite reduced intensity chemotherapy for hematopoietic stem cell transplantation in children and young adults. Bone Marrow Transplant. 2016;51:980-4.

Osho L. Sex matters: from sex to superconsciousness. New York: St Martin's Griffin; 2002.

Passweg JR, Baldomero H, Bader P, Bonini C, Cesaro S, Dreger P, Duarte RF, Dufour C, Kuball J, Farge-Bancel D, Gennery A, Kröger N, Lanza F, Nagler A, Sureda A, Mohty M. Hematopoietic stem cell transplantation in Europe 2014: more than 40000 transplants annually. Bone Marrow Transplant. 2016. Advance online publication 22 Feb 2016. doi:10.1038/bmt.2016.20.

Phipps S, Rai SN, Leung WH, Lensing S, Dunavant M. Cognitive and academic consequences of stemcell transplantation in children. J Clin Oncol. 2008;26(12):2027-33.
Pini S, Hugh-Jones S, Gardner PH. What effect does a cancer diagnosis have on the educational engagement and school life of teenagers? A systematic review. Psychooncology. 2012;21(7):685-94.

Pini S, Gardner P, Hugh-Jones S. The impact of a cancer diagnosis on the education engagement of teenagers - patient and staff perspective. Eur J Oncol Nurs. 2013;17(3):317-23.

Quinn B. Sexual side effects of cancer treatments and the person living with cancer. In: Brandenburg D, Grover L, Quinn B, editors. Intimacy and sexuality for cancer patients and their partners: Pan Birmingham Cancer Psychology Services; 2010. p. 22-32.

Richards M, Corner J, Maher J. The National Cancer Survivorship Initiative: new and emerging evidence on the ongoing needs of cancer survivors. British Journal of Cancer. 2013;105:S1-4.

Rizzo DJ, Curtis RE, Socié G, Sobocinski KA, Gilbert E, Landgren O, Travis LB, Travis WD, Flowers MED, Friedman DL, Horowitz MM, Wingard JR, Deeg JH. Solid cancers after allogeneic hematopoietic cell transplantation. Blood. 2009;113:1175-83.

Rusiewicz A, DuHamel KN, Burkhalter J, Ostroff J, Winkel G, Scigliano E, Papadopoulos E, Moskowitz C, Redd W. Psychological distress in long-term survivors of hematopoietic stem cell transplantation. Psychooncology. 2008;17(4):329-37.

Russmann S, Curkovic I, Huber M. Adverse reactions and risks associated with non-compliance. Ther Umsch. 2010;67(6):303-7.

Savani B, Griffith M, Jagasia S, Lee SJ. How i treat late effects in adults after allogeneic stem cell transplantation. Blood. 2011;117:3002-9.

Schover LR. Sexuality and fertility after cancer. New York: John Wiley \& Sons; 1997.

Snyder C, Harris C, Anderson J, Holleran S, Irving L, Sigmon S, Yoshinobu L, Gibb J, Langelle C, Spelten E, Spragers M, Verbeek J. Factors reported to influence the return to work of cancer survivors: a literature review. Psycho-Oncology. 2002;11:124-31.

Socié G, Stone JV, Wingard JR, Weisdorf D, HensleeDowney J, Bredeson C, Cahn J-Y, Passweg JR, Rowlings PA, Schouten HC, Kolb H-J, Bender-Götze C, Camitta BM, Godder K, Horowitz MM, Wayne AS, Klein JP, for the Late Effects Working Committee of the International Bone Marrow Transplant Registry. Long-term survival and late deaths after allogeneic bone marrow transplantation. $\mathrm{N}$ Engl J Med. 1999;341:14-21.

Tomblyn M, Chiller T, Einsele H, Gress R, Sepkowitz K, Storek J, Wingard JR, Young JH, Boeckh MA. Guidelines for preventing infectious complications among hematopoietic cell transplantation recipients: a global perspective. Biol Blood Marrow Transplant. 2009;15:1143-238.

Tomlinson D, Kline N. In: Tomlinson D, Kline N, editors. Pediatric oncology nursing advanced clinical handbook. Berlin Heidelberg: Springer-Verlag; 2010. 
Treanor C, Santin O, Mills M, Donnelly M. Cancer survivors with self-reported late effects: their health status, care needs and service utilisation. Psychooncology. 2013;22(11):2428-35. pon.3304. Epub 2013 May 16 https://doi.org/10.1002/

Twigg J. Bathing: the body and community care. London: Routledge; 2000.

Waddell G, Burton A. Is work good for your health and wellbeing? London: The Stationary Office; 2006.

Wells M, Williams B, Firnigl D, Lang H, Coyle J, Kroll T, MacGillivray S. Supporting 'work-related goals' rather than 'return to work' after cancer? A systematic review and meta-synthesis of 25 qualitative studies. Psycho-Oncology. 2013;22:1208-19. https://doi. org/10.1002/pon.3148.
Williams SJ. Medicine and the body. London: Sage Publications; 2003.

World Health Organisation. Adherence to long-term therapies, evidence for action. Geneva: World Health Organization; 2003.

\section{Useful Resources}

EBMT Swiss Nurses Group. Adherence to oral antitumour therapies. 2011.

Open Access This chapter is licensed under the terms of the Creative Commons Attribution 4.0 International License (http://creativecommons.org/licenses/by/4.0/), which permits use, sharing, adaptation, distribution and reproduction in any medium or format, as long as you give appropriate credit to the original author(s) and the source, provide a link to the Creative Commons license and indicate if changes were made.

The images or other third party material in this chapter are included in the chapter's Creative Commons license, unless indicated otherwise in a credit line to the material. If material is not included in the chapter's Creative Commons license and your intended use is not permitted by statutory regulation or exceeds the permitted use, you will need to obtain permission directly from the copyright holder. 